УДК 338.46

\title{
ПУТИ СОВЕРШЕНСТВОВАНИЯ \\ ФУНКЦИОНИРОВАНИЯ ГЕРОНТОЛОГИЧЕСКОГО ЦЕНТРА \\ В УСЛОВИЯХ СОЗДАНИЯ РЕГИОНАЛЬНОЙ СИСТЕМЫ ДОЛГОВРЕМЕННОГО УХОДА
}

Руденко Марина Николаевна д.э.н., проф.

Бергфельд Александра Юрьевна магистрант

ФГАОУ ВО «Пермский национальный исследовательский университет»

Аннотация: Проблема старения населения в настоящее время достаточно актуальна для любой страны мирового пространства, поэтому ее решение находится в центре внимания как всей страны и ее регионов, так и отдельных субъектов системы социальных услуг. На основе анализа факторов внешней и внутренней среды регионального геронтологического центра в статье рассмотрены основные проблемы, с которыми сталкиваются субъекты новой системы долговременного ухода в России, и, в частности, в Пермском крае. Предлагаются определенные пути повышения эффективности геронтологического центра.

Ключевые слова: старшее поколение, геронтологический центр, система долговременного ухода, инновационные подходы оказания социальных услуг.

\section{WAYS TO IMPROVE THE FUNCTIONING \\ OF THE GERONTOLOGICAL CENTER IN THE CONTEXT OF THE CREATION OF A REGIONAL LONG-TERM CARE SYSTEM}

\section{Rudenko Marina Nikolaevna Bergfeld Alexandra Yurievna}

\footnotetext{
Abstract: The problem of population aging is currently quite relevant for any country in the world space, so its solution is in the center of attention of both the 
whole country and its regions, and individual subjects of the social services system. Based on the analysis of the factors of the external and internal environment of the regional gerontological center, the article considers the main problems faced by the subjects of the new system of long-term care in Russia, and, in particular, in the Perm Territory. Certain ways to increase the efficiency of the gerontology center are proposed.

Keywords: older generation, gerontology center, long-term care system, innovative approaches to the provision of social services.

Направленность государства на создание условий для активного долголетия граждан является глобальным трендом, который связан с увеличением продолжительности жизни населения во всем мире. При этом наиболее важными факторами активного долголетия можно назвать здоровье и здоровьесбережение.

Не малое значение для реализации практик активного долголетия имеет наличие комфортной в отношении пожилых людей и богатой возможностями окружающей среды, в частности наличие различных форм активного досуга и системы непрерывного обучения. Поэтому в качестве ключевых задач современного российского общества выступает признание того, что люди старшего поколения имеют особую ценность, и забота о них является объективной необходимостью. В связи с этим, стоит преодолевать негативные стереотипы старости, а также дискриминацию по отношению к представителям старшего поколения, формировать благоприятную среду, а также интеграцию в общественную жизнь представителей старшего поколения, которых по данным нацпроекта «Демография», в России около 28 млн. лиц, которые нуждаются в активной заботе общества [1].

Актуальность развития долговременной помощи связана с ростом числа людей, которые относятся к пожилой возрастной категории. По оценкам Финансового университета при правительстве РФ, около 3,7 млн. пожилых людей нуждаются в социальном обслуживании, в то время как получают его только 1,8 млн. человек [2]. Для Пермского края развитие данного направления также актуально, что связано с ростом населения пожилого возраста: из 2 миллионов шестисот тридцати тысяч жителей Пермского края, 801000 человек - получатели пенсии [3]. 
С 2018 году частью Национального проекта «Демография» стало создание системы долговременного ухода, пилотные проекты по его внедрению проводятся в регионах [1]. Система долговременного ухода - это комплексная программа поддержки людей, полностью или частично утративших способность к самообслуживанию: в рамках программы оказываются социальные услуги и медицинская помощь в стационарной или полустационарной форме, а также на дому - с привлечением сиделок.

Среди основных целей, поставленных перед системой долговременного ухода в России, ставятся: увеличение ожидаемой продолжительности здоровой жизни на основе достижение максимально возможного качества жизни и сохранение жизненных потребностей для людей, частично или полностью утративших способность к самостоятельному уходу, поддержка родственников и людей, осуществляющих уход за пожилым человеком, сохранение независимости, самостоятельности, автономности пожилого человека и др. [4]. Реализация поставленных целей предполагается на основе стационарозамещающих технологий, предусматривающих как семейное социальное и медицинское обслуживание пациентов на дому, так и вовлечение патронажа, сиделок.

В программе принимают участие такие сферы системы отечественного здравоохранения как гериатрия, паллиатив и реабилитология - значимость этих секторов обусловлена тем, что в указанных организациях граждане пожилого возраста и инвалиды могут получать навыки самостоятельного проживания.

Однако, на сегодня ситуация в отношении пожилых людей характеризуется противоречием между признанием приоритетной задачей увеличение продолжительности и повышением уровня качества жизни старшего поколения и развитием существующей системы долговременного ухода, которая является неустойчивой и не обеспечивает должного уровня социального обслуживания людей пожилого возраста [5]. Соответственно, основная проблема - поиск инструментов развития системы долговременного ухода граждан пожилого возраста в стране и отдельно в регионах.

Одним из крупных участников региональной системы социальной поддержки населения пожилого возраста Пермского края является ПКГАУ «Верхне-Курьинский геронтологический центр» (далее - Центр»), который в соответствие с организационно-правовым статусом является краевым государственным автономным учреждением. Данный центр существует с 
2003 года, был создан вместо Верхне-Курьинского дома-интерната для престарелых и инвалидов.

В основном, пациентами ПКГАУ «Верхне-Курьинский геронтологический центр» являются лица с выраженными или значительно выраженными ограничениями способности к самообслуживанию и передвижению, средний возраст которых составляет около 69 лет. Основным продуктом учреждения являются услуги долговременного ухода за престарелыми и инвалидами: на сегодня в Центре предлагаются услуги по уходу за пожилыми людьми, временное пребывание в центре, необходимые лечебные и поддерживающие процедуры.

Для оценки эффективности управления в ПКГАУ «Верхне-Курьинский геронтологический центр» были рассмотрены основные факторы внутренней среды, определяющие следующие стороны развития учреждения: организационную и социальную, финансово-экономическую, производственнотехнологическую. Данная оценка позволила сделать вывод о том, что Центр имеет свои сильные стороны, которые позволяют оставаться ему конкурентоспособным, и слабые стороны, над которыми следует поработать.

Так проведенная оценка свидетельствует о том, что эффективность деятельности аппарата управления за 2020 г. снизилась по сравнению с предыдущим периодом, руководители среднего звена выполняют больше функций, чем следует, соответственно, требуется пересмотр и оптимизация выполняемых функций. И, хотя в совокупности, сильные стороны формируют хорошую базу Центра как управляемой системы, все же проблемы в финансовом состоянии на протяжении последних нескольких лет свидетельствует о том, что эффективность его работы падает. Соответственно, логично предположить, что большая часть проблем находится в сфере управления.

Вместе с тем у Центра существуют возможности для развития деятельности и некоторые угрозы со стороны внешней среды. Часть угроз связана с неопределенностью внешней среды деятельности, защитой от которых может стать повышение адаптивных способностей предприятия, включающее систематический мониторинг ситуации.

Для того, чтобы решить снизить или устранить риски внешней среды, связанные с реформированием национальной системы долговременного ухода за пожилыми, учреждению необходимо разработать план мероприятий и 
действий, которые помогут сохранить и увеличить его эффективность как для учредителей, так и для социально-экономического развития г. Перми и Пермского края. Финансовые угрозы следует компенсировать через эффективность работы Центра, что даст необходимый запас прочности.

Грамотная политика управления человеческим капиталом значительно повысит привлекательность Учреждения как работодателя, в том числе, долгосрочного, что позволит привлечь кадров желаемой квалификации либо активно применять практики внутрифирменного обучения. Своевременное выявление трендов, гибкость реакции и повышение качества человеческого капитала положительно скажутся на конкурентоспособности предприятия, так как являются основой многих конкурентных преимуществ.

Таким образом, проведенный анализ эффективности управления ПКГАУ «Верхне-Курьинский геронтологический центр» позволил сделать вывод о необходимости изменения подхода к управлению Центром.

Ключевая проблема развития ПКГАУ «ВКГЦ»: недостаточно широкий спектр и качество оказываемых услуг, недостаточная квалификация кадров, а также недостаточно сформированная система контроля и мотивации, что делает целесообразным разработку и реализацию иной системы управления, которая поможет решить существующие проблемы.

Учреждение развито хорошо, крепко «стоит на ногах», не нужно прибегать к радикальному изменению целей. Поэтому тактической целью автор видит как удовлетворение потребностей наиболее нуждающихся в социальной защите категорий населения старшего поколения, а также расширение его численного охвата.

Задачами развития Центра являются:

- адаптация к изменениям во внешней среде - процессам становления и развития новой системы долговременного ухода;

- увязка имеющихся ресурсов с изменениями внешней среды;

- выявление и мониторинг возникающих в ходе реализации стратегии проблем;

- координация работы различных органов управления и общественных организаций;

- мониторинг изменений мероприятий социальной политики на уровне региона и страны. 
Для повышения эффективности ПКГАУ «ВКГЦ» и совершенствования управления в соответствие с тенденциями социально-экономического развития региона предложено:

1. Обучение руководителей ПКГАУ «ВКГЦ» и его филиалов (курсы повышения квалификации, переподготовка, базовое высшее образование).

2. Создание возможностей для качественного предоставления услуг:

- снижение нагрузки на одного специалиста, организация волонтерской/семейной (внестационарной) поддержки, повышение квалификации специалистов (обучение технологиям современного отслеживания изменений законодательства;

- расширение услуг, оказываемых на дому, вне стационара, работа с семьями, волонтерами;

- специализация;

- клиентоориентированность.

3. Обновление материально-технической базы организации (включить в смету расходов закупку современного, реабилитационного оборудования), что направлено на обеспечение максимально комфортного проживания граждан пожилого возраста и инвалидов в Центре;

4. Повышение мотивации работников - связать вознаграждение за работу с достижением результатов, создать благоприятную атмосферу внутри Учреждения в целом.

Для решения обозначенных проблем предложены следующие инновационные подходы:

- проект «Активная семейная поддержка»;

- механизм управления системой кадров учреждения социального обслуживания, который позволит поэтапно решать поставленные задачи и обеспечит устойчивый социальный эффект на инновационной основе;

Основным ориентиром повышения эффективности функционирования Центра должны стать появляющиеся на сегодня инновационные технологии социального обслуживания, целью которых является в первую очередь компенсация дефицита самообслуживания. В качестве приоритетного направления реализации стратегии выступают мероприятия по развитию профессиональных компетенций специалистов ПКГАУ «ВКГЦ». Связано это с тем, что непрофильная подготовленность кадров, отсутствие механизма управления системой кадров учреждения не позволяет оказывать услуги по 
принципу «одного окна», а значит и повысить качество оказываемых услуг и как следствие повысить социально-экономический эффект.

Кроме того, широкий спектр проблем обслуживаемых семей с представителями старшего поколения, не всегда позволяет качественно оказывать услуги по их сопровождению, во время оказывать помочь в критических ситуациях, что не позволяет сохранять семьи. Инновационным решением для повышения качества оказываемых услуг станет организация и внедрение работы по активной семейной поддержке с командой высококвалифицированных специалистов.

«Активная семейная поддержка» подразумевает, в первую очередь, создание в ПКГАУ «ВКГЦ» профессиональной команды по оказанию помощи семьям, обеспечивающим долговременный уход за престарелыми гражданами дома (вне стационара). Модель работы с семьей тиражируется на все районы города, позволяет наиболее полно оказать комплекс услуг, избежать формального подхода при работе с семьей за счет высоких компетенций помогающего специалиста и своевременной помощи.

Якорной услугой ПКГАУ «ВКГЦ» является патронаж семьи на дому, который обеспечивает первичные потребности нуждающихся престарелых членов семей, создавая крепкую психологическую основу помощи и эффективно отвечая на запрос целевой группы, но не является достаточной. Основу работы с семьей составляет комплексное сопровождение командой профессионалов по принципу «одного окна».

Наряду с открытием службы сиделок можно предусмотреть в ПКГАУ «ВКГЦ» организацию Школы «Забота о близких». Цель ее деятельности - обучение родственников пожилых граждан приемам и техникам ухода за ними. Интерес к занятиям в школе потенциально могут проявить не только родственники обслуживаемых граждан, но социальные работники учреждения.

Организация комплексного подхода предполагает межведомственное взаимодействие ПКГАУ «ВКГЦ» с учреждениями здравоохранения, социального обслуживания, Управлением пенсионного фонда - такое тесное взаимодействие между собой учреждений, организаций, предприятий - всех участников социального кластера Пермского края приведет к повышению эффективности обмена знаниями, информацией, ресурсами и опытом. 
Информирование граждан целесообразно организовать через интернет-группу сети «ВКонтакте», сайт учреждения, муниципальные газеты.

Таким образом, предлагаемые проектные решения «Активная семейная поддержка» и «Механизм управления системой кадров учреждения социального обслуживания» позволят поэтапно решать поставленные задачи и обеспечат устойчивый социальный эффект на инновационной основе.

Подводя итоги, следует отметить, что создание системы долговременного ухода - необходимый и возможный шаг для улучшения качества жизни пожилых граждан. Еще многое предстоит сделать для того, чтобы пожилые люди чувствовали себя комфортно и жили долго.

\section{Список литературы}

1. Паспорт национального проекта «Демография» [Электронный pecypc]: утв. Президиумом Совета при Президенте Российской Федерации по стратегическому развитию и национальным проектам. URL: http://www.consultant.ru/document/cons_doc_LAW_317388/(дата обращения: 12.09.2021).

2. Доклад о результатах комплексного мониторинга социальноэкономического положения пожилых людей в 2019 году [Электронный ресурс]. URL: https://mintrud.gov.ru/social/270. (дата обращения 02.09.2021);

3. Москаленко В.Ф., Грузева Т.С. Современные медико-социальные проблемы старения населения и подходы к их решению. URL: https: //cyberleninka. ru/article/n/sovremennye-mediko-sotsialnye-problemystareniyanaseleniya-i-podhody-k-ih-resheniyu (дата обращения 30.09.2021) .

4. Москаленко В.Ф., Грузева Т.С. Современные медико-социальные проблемы старения населения и подходы к их решению. URL: https: //cyberleninka. ru/article/n/sovremennye-mediko-sotsialnye-problemystareniyanaseleniya-i-podhody-k-ih-resheniyu (дата обращения 30.09.2021) .

5. Дерябин А.В., Уваровский Г.С. Повышение эффективности работы бюджетного учреждения социальной сферы // Социально-экономические, гуманитарные и политические тренды глобализации: материалы XXX междунар. науч.-практ. конф., в 3-х ч. Ч. II. Челябинск: Урал. соц-экон. ин-т (ф) ОУП ВПО «АТиСО», 2021. С. 83-88.

6. Богданова Л.А., Филатова Е.В. Создание системы долговременного ухода за гражданами пожилого возраста и инвалидами в СПб ГБУ КЦСОН Московского района // Социальная работа: теория, методы, практика. 2020. 
Вып. 2: Реализация комплексной системы долговременного ухода за гражданами пожилого возраста в учреждениях социального обслуживания населения Санкт-Петербурга. С. 85-89.

7. Официальный сайт Федеральной службы государственной статистики [Электронный ресурс]. - Старшее поколение. URL: http://www.gks.ru/ statistics/population/generation/ (дата обращения 09.09.2021);

8. Росстат: К 2025 году 40,5 россиян не смогут ухаживать за собой // ВестиРама.Ру. ФГУП ВГТРК ГТРК «Оренбург». URL: https://vestirama.ru/novosti/rosstat-rossiyane-ne-smogut-uhazhivat-31032019.html (дата обращения 01.10.2021).

9. Старшее поколение [Электронный ресурс] // Федеральная служба государственной статистики. URL: https://rosstat.gov.ru/folder/13877?print=1 (дата обращения: 05.10.2021).

(C) М.Н. Руденко, А.Ю. Бергфельд, 2021 